\title{
Physical activity promotion in Latin American populations: a systematic review on issues of internal and external validity
}

Karla I Galaviz', Samantha M Harden², Erin Smith³, Kacie CA Blackman, Leanna M Berrey ${ }^{5}$, Scherezade K Mama ${ }^{6}$, Fabio A Almeida ${ }^{7}$, Rebecca E Lee ${ }^{8}$ and Paul A Estabrooks ${ }^{9^{*}}$

\begin{abstract}
The purpose of this review was to determine the degree to which physical activity interventions for Latin American populations reported on internal and external validity factors using the RE-AIM framework (reach \& representativeness, effectiveness, adoption, implementation, maintenance). We systematically identified English (PubMed; EbscoHost) and Spanish (SCIELO; Biblioteca Virtual en Salud) language studies published between 2001 and 2012 that tested physical activity, exercise, or fitness promotion interventions in Latin American populations. Cross-sectional/descriptive studies, conducted in Brazil or Spain, published in Portuguese, not including a physical activity/fitness/exercise outcome, and with one time point assessment were excluded. We reviewed 192 abstracts and identified 46 studies that met the eligibility criteria (34 in English, 12 in Spanish). A validated 21-item RE-AIM abstraction tool was used to determine the quality of reporting across studies (0-7 = low, 8-14= moderate, and 15-21 = high). The number of indicators reported ranged from 3-14 (mean $=8.1 \pm 2.6$ ), with the majority of studies falling in the moderate quality reporting category. English and Spanish language articles did not differ on the number of indicators reported (8.1 vs. 8.3, respectively). However, Spanish articles reported more across reach indicators (62\% vs. $43 \%$ of indicators), while English articles reported more across effectiveness indicators (69\% vs 62\%). Across RE-AIM dimensions, indicators for reach (48\%), efficacy/effectiveness (67\%), and implementation (41\%) were reported more often than indicators of adoption (25\%) and maintenance (10\%). Few studies reported on the representativeness of participants, staff that delivered interventions, or the settings where interventions were adopted. Only $13 \%$ of the studies reported on quality of life and/or potential negative outcomes, $20 \%$ reported on intervention fidelity, and $11 \%$ on cost of implementation. Outcomes measured after six months of intervention, information on continued delivery and institutionalization of interventions, were also seldom reported. Regardless of language of publication, physical activity intervention research for Latin Americans should increase attention to and measurement of external validity and cost factors that are critical in the decision making process in practice settings and can increase the likelihood of translation into community or clinical practice.
\end{abstract}

Keywords: External validity, Latin America, Physical activity, Review, Interventions

\footnotetext{
* Correspondence: estabrkp@vt.edu

${ }^{9}$ Professor of Human Nutrition, Foods, \& Exercise, Virginia Tech, Co-Director

of the Fralin Translational Obesity Research Center, Professor of Family

Medicine, Virginia Tech Carilion School of Medicine, Senior Director of

Research, Carilion Clinic, 1 Riverside Circle SW Suite \#104, Roanoke, VA 24016,

USA

Full list of author information is available at the end of the article
}

\section{Biomed Central}

(c) 2014 Galaviz et al.; licensee BioMed Central Ltd. This is an Open Access article distributed under the terms of the Creative Commons Attribution License (http://creativecommons.org/licenses/by/2.0), which permits unrestricted use, distribution, and reproduction in any medium, provided the original work is properly credited. The Creative Commons Public Domain Dedication waiver (http://creativecommons.org/publicdomain/zero/1.0/) applies to the data made available in this article, unless otherwise stated. 


\section{Introduction}

The health consequences of physical inactivity are well documented $[1,2]$ and contribute to the global epidemic of non-communicable diseases [3]. Physical inactivity is the fourth leading risk factor for mortality and affects one third of the global adult population [4]. In Latin America, $43 \%$ of the population older than 15 years is inactive (defined as fewer than 30 min of moderate-intensity physical activity on at least five days every week), with the prevalence of physical inactivity ranging from 16\% in Guatemala to 68\% in Argentina [5].

A number of intervention strategies for improving physical activity among Latin American populations have been implemented to ameliorate this problem [6]. Initiatives like Ciclovia [7,8], Agita [9], and GUIA [10] have focused on increasing active transportation, community-wide physical activity, and the implementation of evidence-based physical activity strategies across Latin American countries. A previous systematic review of physical activity promotion research across Latin America completed by Hoehner and colleagues summarized much of this research [6] from the perspective of the Guide to Community Preventive Services [11]. They found that there was insufficient evidence to make a recommendation for any intervention that focused on improving physical activity in adults. Poor methodological rigor resulting in low internal validity was noted as the primary limitation of the studies included in the review [6]. To improve the likelihood of having a public health impact it is necessary to also understand external validity and the influence that context may have on knowledge translation and engagement of participants who are representative of the population of interest [12-14]. Although Hoehner and colleagues updated their review to include the reporting of external validity factors [15], the majority of the studies they reviewed were from Brazil, a large, economically and culturally different country than the rest of Latin America.

The RE-AIM framework [16-18] was developed to provide researchers with an evaluation approach that balances internal and external validity factors. RE-AIM is an acronym that addresses reach and effectiveness at the individual level, adoption and implementation at the organizational level, and maintenance at the individual and organizational levels [19]. The RE-AIM framework has been used to review the reporting of internal and external validity of physical activity interventions using behavior change theories [20], school-based strategies [21], telephone-delivered strategies [22], workplace interventions [23], and interventions targeting cancer survivors [24]. Recommendations from these reviews are similar the reporting of external validity factors should be improved to promote the translation of these strategies into practice. The purpose of this review was to examine the degree to which reports of physical activity interventions for Latin Americans focus on internal and external validity factors using the RE-AIM framework. For the purpose of this review, Latin Americans were defined as Mexicans, Mexican-Americans, Latinos and Hispanics receiving interventions in the United States or in a Spanish-speaking Latin American country.

\section{Methods}

\section{Selection of studies}

We systematically identified English and Spanish language studies published between 2001 and 2012 that tested the effectiveness of physical activity, exercise, or fitness interventions in Latin American populations. This time frame was based on the release and dissemination of the seminal RE-AIM article to increase the reporting of internal and external validity factors [16]. Studies testing intervention effectiveness, using quasi-experimental or experimental designs, focused on Hispanic, Mexican, Latin American, and Mexican-American children and adults, with an exercise or physical activity or fitness outcome were included (see Table 1). Cross-sectional and descriptive studies, conducted in Brazil or Spain, published in Portuguese language, not including an exercise or physical activity or fitness outcome, and with one time point assessment were excluded. We searched PubMed and EbscoHost to identify studies published in English and SCIELO and Biblioteca Virtual de Salud to identify studies published in Spanish. The following search terms were used in English and Spanish: Physical activity, fitness, exercise, adherence, intervention, program, policy, Latino, Hispanic, Mexican, and Mexican-American (see search strings in Additional file 1).

Randomly selected pairs of reviewers independently screened title and abstracts for each English citation, and eligibility of Spanish studies was determined by one

\section{Table 1 Inclusion criteria for articles}

\begin{tabular}{lc}
\hline Data type & Inclusion criteria \\
\hline Participants & $\begin{array}{c}\text { Mexican, Latin American, Hispanic, and } \\
\text { Mexican American children and adults } \\
\text { Language } \\
\text { English } \\
\text { Spanish }\end{array}$ \\
$\begin{array}{c}\text { Used experimental or quasi-experimental } \\
\text { design }\end{array}$ \\
$\begin{array}{c}\text { Any comparator including active } \\
\text { control, inactive control, or } \\
\text { pre- and post-measure }\end{array}$ \\
$\begin{array}{c}\text { Mssessments } \\
\text { Primary outcome (s) (at least } \\
\text { one of these outcomes) }\end{array}$ \\
points (pre and post assessment) \\
Physical activity \\
Exercise \\
Fitness
\end{tabular}


pair of reviewers. Disagreements were discussed and resolved by consensus. Inter-rater reliability for including/excluding articles based on abstract screening was Kappa $=.80$. The original search produced 368 articles (241 English and 127 Spanish articles). A total of 73 articles were selected for full text review (53 in English and 20 in Spanish), which led to the exclusion of 27 additional studies that did not meet inclusion criteria. Forty-six articles met the inclusion criteria (34 in English and 12 in Spanish) and were included in the final review (see Figure 1). Companion articles reporting on process evaluations of the included studies, identified either through the initial search or referenced in the reviewed articles, were also assessed.

\section{RE-AIM criteria}

We used a validated 21-item tool to code articles on REAIM dimensions [25,26]. This tool captures the extent to which intervention studies report on internal and external validity indicators. Additional items $(n=29)$ were included to provide more detail about the methods used across the RE-AIM dimensions and are described below [27]. A total of 50 RE-AIM items were used to code articles for reach $(n=12)$, efficacy/effectiveness $(n=8)$, adoption $(n=15)$, implementation $(n=9)$ and maintenance $(n=6)$.

\section{Reach}

To evaluate the reporting of reach, articles were coded on the method to identify the target population, inclusion

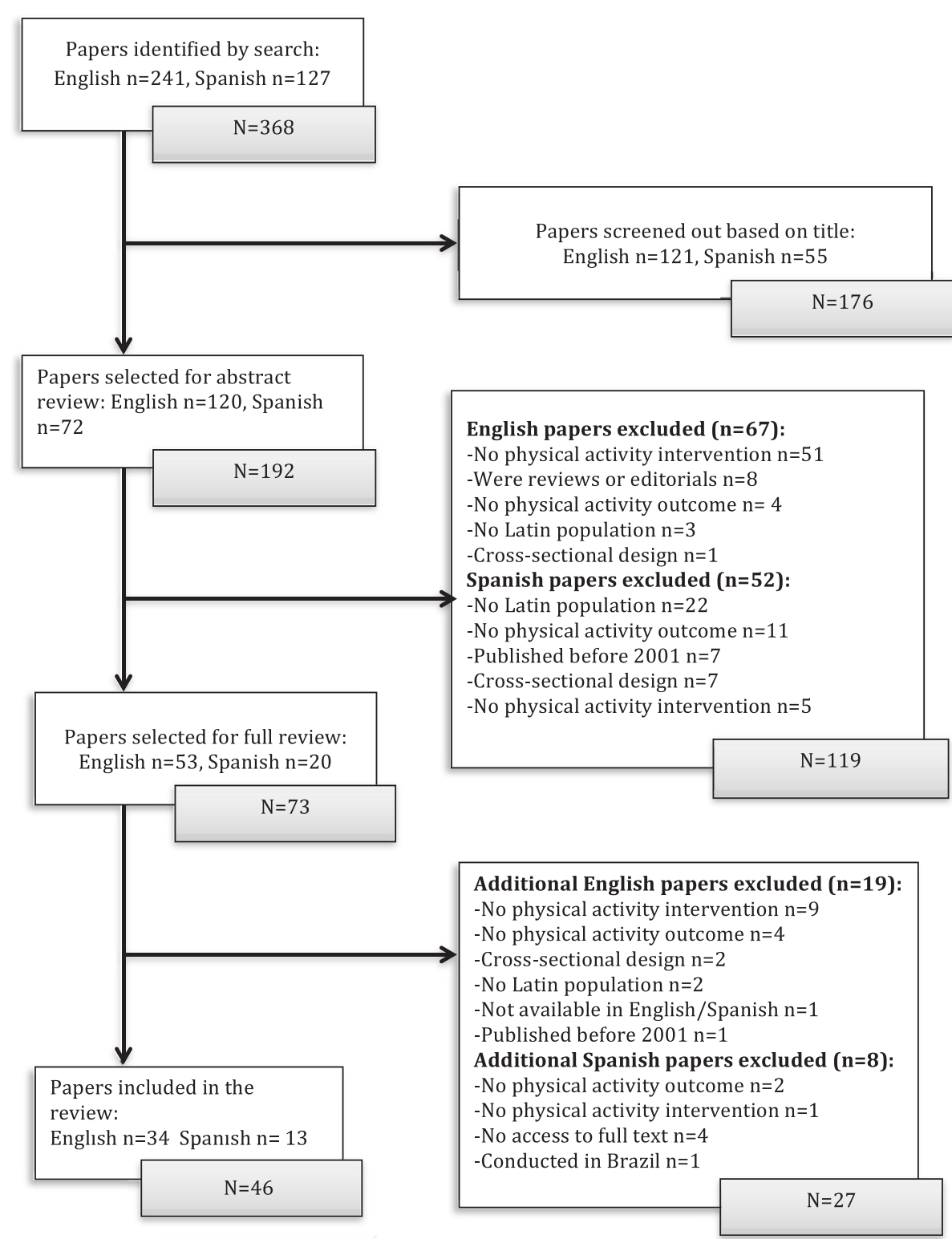

Figure 1 Selection of physical activity intervention studies for systematic review. 
and exclusion criteria, participation rate and characteristics of participants and non-participants. In addition to the original validated items, we also coded articles on whether they reported characteristics of the target population, recruitment strategy used, cost of recruitment and the use of qualitative methods to measure reach.

\section{Efficacy/effectiveness}

We included reports of physical activity interventions delivered under real world conditions (effectiveness trials), and reports of interventions delivered under optimum conditions (efficacy trials) [28]. Validated items used to code this dimension included the assessment of changes in the primary outcome, the use of present at follow-up versus an intention-to-treat approach for data analysis, measures of quality-of-life or potential negative outcomes, and the reporting of percentage attrition. Additional items included study design, type of trial, results at program completion, comparison of outcome to public health goal, imputation procedures, mediator and moderator variables, cost-effectiveness and use of qualitative methods for assessing efficacy/effectiveness.

\section{Adoption}

Articles were reviewed to identify whether adoption at the setting and staff levels was reported. Validated items were used to code whether articles provided a description of intervention location, a description of the staff who delivered the intervention, the method to identify the delivery staff, the inclusion and exclusion criteria for setting or staff, and the setting or staff participation rate. Additional items were used to code whether articles reported on the method to identify the intervention setting, level of expertise of the delivery staff, organizational spread (i.e., adoption in settings across an organization) and characteristics of adoption and non-adoption of settings and staff. Finally, items were included to code articles for reporting on measures of cost of adoption, dissemination beyond originally planned (spread of intervention within or outside an organization), and use of qualitative methods to measure adoption were also included.

\section{Implementation}

Items assessed whether articles reported the duration and frequency of the intervention, the extent to which the protocol was delivered as intended, and the cost of delivery. Additional implementation indicators used include whether articles reported the theoretical framework of the intervention, the consistency of implementation across settings and delivery agents, the degree to which the participants received intervention components, and the use of qualitative methods for measuring implementation.

\section{Maintenance}

Maintenance was coded at the individual and organizational levels. At the individual level, articles were coded for whether the study included assessments of intervention outcomes at six or more months after the completion of the intervention and participant attrition levels. At the organizational level, we focused on whether the articles documented sustained intervention delivery and whether they included information about the institutionalization of the program. Reports about program alignment to organization mission, continuation, discontinuation and modification of the program, and use of qualitative methods to measure maintenance were also coded as present or absent.

\section{Coding protocol}

Different pairs of reviewers independently coded each English and Spanish language article for the presence or absence (Yes-present or No-absent) of the RE-AIM indicators described above. Each pair of reviewers met to discuss any discrepancies in coding; resolution was completed by direct reference to the research article. If no agreement could be reached, a third reviewer was consulted. Data exploration included frequency counts and percentages across the RE-AIM indicators. To allow for comparisons to other RE-AIM reviews, the overall quality of RE-AIM reporting across articles was determined based on the degree to which articles reported on the 21 items in the validated tool. Articles were then classified as low $(0-7)$, moderate $(8-14)$ and high $(15-21)$ quality.

\section{Results}

Of the 46 included articles, 18 were experimental studies [29-46] and 28 were quasi-experimental studies [47-74]. On average, studies reported on $8.0( \pm 2.6)$ of the 21 validated RE-AIM indicator items, with a range of 3 to 14 indicators reported (Table 2). The quality of RE-AIM reporting was low in $41 \%$ of articles and moderate in over half of articles (59\%). English and Spanish language articles did not differ on the average number of RE-AIM indicators reported (8.1 vs. 8.3). Most of the studies were conducted in community settings $(n=29)$. Fewer studies were conducted in clinical settings $(n=9)$, and eight studies did not report setting. Information about the studies included is presented in an Additional file 2: Table S1.

\section{Reach}

The proportion of reach indicators reported across studies was $47 \%$, where Spanish studies had a higher proportion of indicators reported than English studies (62\% vs. $43 \%$ respectively). Overall, the reach indicators reported in the majority of the studies were those concerned with internal validity, which included the method to identify the target 
Table 2 Number of RE-AIM validated indicators $(n=21)$ reported by each article $(n=46)$

\begin{tabular}{|c|c|c|c|c|c|c|}
\hline Author/year/country & $\begin{array}{l}\text { Reach } \\
(n=5)^{*}\end{array}$ & $\begin{array}{l}\text { Effectiveness/Efficacy } \\
\qquad(n=4)\end{array}$ & $\begin{array}{c}\text { Adoptio } \\
(n=6)\end{array}$ & $\begin{array}{l}\text { Implementatio } \\
\quad(n=3)\end{array}$ & $\begin{array}{c}\text { Maintenanc } \\
(n=3)\end{array}$ & $\begin{array}{c}\text { Total } \\
(n=21)\end{array}$ \\
\hline Alhassan et al., 2007 & 3 & 3 & 2 & 2 & 0 & 10 \\
\hline \multicolumn{7}{|l|}{ United States } \\
\hline Atehortúa et al., 2011 & 5 & 4 & 0 & 1 & 0 & 10 \\
\hline \multicolumn{7}{|l|}{ Colombia } \\
\hline Ayala et al., 2011 & 3 & 3 & 4 & 1 & 1 & 12 \\
\hline \multicolumn{7}{|l|}{ United States } \\
\hline Bacardí et al., 2005 & 1 & 3 & 2 & 1 & 0 & 7 \\
\hline \multicolumn{7}{|l|}{ Mexico } \\
\hline Balcázar et al., 2005 & 1 & 3 & 3 & 2 & 0 & 9 \\
\hline \multicolumn{7}{|l|}{ United States } \\
\hline Barroso et al., 2009 & 1 & 0 & 3 & 1 & 0 & 5 \\
\hline \multicolumn{7}{|l|}{ United States } \\
\hline Bonhauser et al., 2005 & 0 & 3 & 3 & 2 & 1 & 9 \\
\hline \multicolumn{7}{|l|}{ Chile } \\
\hline Carreño et al., 2006 & 1 & 3 & 0 & 1 & 0 & 5 \\
\hline \multicolumn{7}{|l|}{ Chile } \\
\hline Coleman et al., 2005 & 2 & 3 & 3 & 1 & 0 & 9 \\
\hline \multicolumn{7}{|l|}{ United States } \\
\hline Coleman et al., 2010 & 2 & 3 & 0 & 2 & 0 & 7 \\
\hline \multicolumn{7}{|l|}{ United States } \\
\hline Coleman et al., 2012 & 3 & 3 & 3 & 1 & 0 & 10 \\
\hline \multicolumn{7}{|l|}{ United States } \\
\hline Colin et al., 2010 & 2 & 3 & 2 & 1 & 0 & 8 \\
\hline \multicolumn{7}{|l|}{ Mexico } \\
\hline Crews et al., 2004 & 0 & 3 & 0 & 1 & 0 & 4 \\
\hline \multicolumn{7}{|l|}{ United States } \\
\hline Dauenhauer and Keating, 2011 & 1 & 2 & 2 & 1 & 0 & 6 \\
\hline \multicolumn{7}{|l|}{ United States } \\
\hline Díaz et al., 2011 & 1 & 1 & 1 & 1 & 1 & 5 \\
\hline \multicolumn{7}{|l|}{ Chile } \\
\hline Dornelas et al., 2008 & 1 & 4 & 3 & 1 & 1 & 10 \\
\hline \multicolumn{7}{|l|}{ United States } \\
\hline Eakin et al., 2007 & 4 & 2 & 3 & 1 & 1 & 11 \\
\hline \multicolumn{7}{|l|}{ United States } \\
\hline Hawthorne et al., 2011 & 3 & 3 & 5 & 2 & 0 & 13 \\
\hline \multicolumn{7}{|l|}{ United States } \\
\hline Ingram, M., 2012 & 2 & 3 & 2 & 1 & 2 & 10 \\
\hline \multicolumn{7}{|l|}{ United States } \\
\hline Kain et al., 2008 & 3 & 3 & 2 & 1 & 1 & 10 \\
\hline \multicolumn{7}{|l|}{ Chile } \\
\hline Kain et al., 2009 & 2 & 3 & 4 & 2 & 1 & 12 \\
\hline \multicolumn{7}{|l|}{ Chile } \\
\hline Keller et al., 2001 & 3 & 1 & 0 & 1 & 0 & 5 \\
\hline
\end{tabular}


Table 2 Number of RE-AIM validated indicators $(n=21)$ reported by each article $(n=46)$ (Continued)

United States

Keller et al., 2008

United States

King et al., 2006

United States

Kong et al., 2010

United States

Lucumí et al., 2006

Colombia

Martyn et al., 2010

United States

Mier et al., 2011

United States

Millard et al., 2011

United States

Molina et al., 2010

Chile

Mosso et al., 2011

Chile

Muñoz and Salazar, 2005

Mexico

O'Connor et al., 2011

United States

Olvera et al., 2010

United States

Ramírez et al., 2011

Colombia

Romero et al., 2008

United States

Romero 2012

United States

Roselló et al., 2001

Costa Rica

Spruijt-Metz et al., 2008

United States

Spruijt-Metz et al., 2009

United States

Staten et al., 2005

United States

Sáenz and Gallegos, 2004

Mexico

Salinas et al., 2005

Chile

3

0

7

3

3

3

4

3

1

1

0

10

10

6

5

7

5

6

Chile 
Table 2 Number of RE-AIM validated indicators $(n=21)$ reported by each article $(n=46)$ (Continued)

\begin{tabular}{|c|c|c|c|c|c|c|}
\hline Treviño et al., 2004 & 3 & 3 & 2 & 1 & 1 & 10 \\
\hline Unites States & & & & & & \\
\hline Wing et al., 2004 & 3 & 4 & 2 & 2 & 1 & 12 \\
\hline
\end{tabular}

${ }^{*} n$ represents the number of indicators included from each dimension.

population (65\%), inclusion (72\%) and exclusion criteria (39\%). Regarding reports about external validity factors, $52 \%$ reported on participation rate, while $11 \%$ reported on the characteristics of participants and non-participants. Only one English article [64] and one Spanish article [47] reported all five reach indicators. Regarding additional reach indicators, $93 \%$ of the studies provided a description of target population, $46 \%$ provided demographic information on the target population, 50\% reported recruitment strategies used, and $46 \%$ reported the target population denominator. None of the studies reported cost of recruitment activities or used qualitative measures of reach.

\section{Efficacy/effectiveness}

On average, the reporting of efficacy/effectiveness components was $67 \%$ across studies and focused on internal validity factors. English studies reported more indicators of efficacy/effectiveness than Spanish studies (69\% vs. $62 \%$, respectively). Results for primary outcome (98\%), use of intention to treat or present at follow-up analysis (84\%), and percent of attrition (78\%) were reported more frequently than other efficacy/effectiveness indicators. Only $13 \%$ of the studies reported having measured quality of life and/or potential negative outcomes, and only three studies reported all effectiveness/efficacy indicators $[47,58,65]$. Regarding additional indicators, few studies reported having compared outcomes to public health goals (15\%), the use of qualitative methods (7\%) and reported on cost-effectiveness (2\%).

\section{Adoption}

Adoption indicator reporting was low (25\% of all studies) and was higher among English language articles (27\%) than Spanish language articles (19\%). Level of expertise of the staff that delivered the intervention was reported in $57 \%$ of the studies, while description of the intervention location and setting/staff participation rate was only reported in $33 \%$ and $15 \%$ of the studies, respectively. The inclusion/exclusion criteria for staff or setting were reported in $17 \%$ of studies, and method to identify the staff that delivered the intervention was reported in $9 \%$ of studies. No studies reported all six adoption indicators; only three studies reported four out of these indicators [48,61,72]. For additional indicators, $76 \%$ of studies reported the setting in which the intervention was delivered, and only $2 \%$ reported on any of the remaining adoption indicators.

\section{Implementation}

The average reporting proportion of implementation indicators across studies was $41 \%$, which largely focused on internal validity factors. English studies reported on implementation slightly more than Spanish studies (42\% vs. 39\%, respectively). Most studies (93\%) reported on intervention dose (i.e. duration). Delivery as intended was reported by $20 \%$ of the studies, and cost of intervention was reported by only $11 \%$ of studies. Only one Spanish study reported on the three implementation indicators [72]. Additional items reported include the timing of intervention contacts (83\%), participant completion rates $(48 \%)$ and the use of a theoretical framework (41\%). Only $15 \%$ of the studies reported the use of qualitative methods for measuring implementation, and one study reported on the consistency of intervention implementation across settings.

\section{Maintenance}

Among RE-AIM dimensions, maintenance reported the least often across all studies. Only $10 \%$ of all studies reported on maintenance, and Spanish studies had slightly higher reports than English studies (14\% vs. 8\%, respectively). Approximately $13 \%$ of studies reported on indicators of organizational level maintenance, $11 \%$ reported on individual outcomes assessed six months after the intervention and $7 \%$ provided information about program institutionalization. None of the studies reported on all three validated indicators of maintenance. Attrition (7\%), use of qualitative methods for measuring maintenance (2\%) and measure of intervention alignment with organizational missions, structure, or resources (4\%) were additional indicators seldom reported. See Table 3 for RE-AIM reporting proportions.

\section{Discussion}

The objective of this systematic review was to assess the degree to which the literature on physical activity interventions focusing on Latin American populations report on internal and external validity factors using the REAIM framework. Overall, the reviewed articles reported most frequently on the RE-AIM dimensions of reach, efficacy/effectiveness and implementation and least frequently on adoption and maintenance. Reporting was similar between English and Spanish language articles. However, Spanish articles were more likely to report on 
Table 3 Proportion of physical activity interventions reporting on RE-AIM indicators

\begin{tabular}{|c|c|c|c|}
\hline \multirow[t]{2}{*}{ RE-AIM indicators } & \multicolumn{3}{|c|}{ Proportion of indicators reported } \\
\hline & English $(n=34)$ & Spanish $(n=12)$ & All $(n=46)$ \\
\hline \multicolumn{4}{|l|}{ Reach } \\
\hline Method to identify target population & $53 \%$ & $100 \%$ & $65 \%$ \\
\hline Inclusion criteria & $71 \%$ & $75 \%$ & $72 \%$ \\
\hline Exclusion criteria & $32 \%$ & $58 \%$ & $39 \%$ \\
\hline Participation rate & $47 \%$ & $67 \%$ & $52 \%$ \\
\hline Characteristics of participants and non-participants & $12 \%$ & $8 \%$ & $11 \%$ \\
\hline Average across Reach components & $43 \%$ & $62 \%$ & $48 \%$ \\
\hline \multicolumn{4}{|l|}{ Efficacy/Effectiveness } \\
\hline Results for primary outcome & $97 \%$ & $100 \%$ & $98 \%$ \\
\hline Intent-to-treat or present at follow up analysis & $88 \%$ & $75 \%$ & $84 \%$ \\
\hline Quality-of-life or potential negative outcome measures & $12 \%$ & $17 \%$ & $13 \%$ \\
\hline Percent attrition & $85 \%$ & $58 \%$ & $78 \%$ \\
\hline Average across Efficacy/Effectiveness components & $69 \%$ & $62 \%$ & $67 \%$ \\
\hline \multicolumn{4}{|l|}{ Adoption } \\
\hline Description of intervention location & $35 \%$ & $25 \%$ & $33 \%$ \\
\hline Description of staff who delivered intervention & $24 \%$ & $8 \%$ & $20 \%$ \\
\hline Method to identify staff who delivered intervention & $9 \%$ & $8 \%$ & $9 \%$ \\
\hline Level of expertise of delivery agent & $62 \%$ & $42 \%$ & $57 \%$ \\
\hline Inclusion/exclusion criteria of delivery agent or setting & $21 \%$ & $8 \%$ & $17 \%$ \\
\hline Adoption rate of delivery agent or Setting & $12 \%$ & $25 \%$ & $15 \%$ \\
\hline Average across Adoption components & $27 \%$ & $19 \%$ & $25 \%$ \\
\hline \multicolumn{4}{|l|}{ Implementation } \\
\hline Intervention duration and frequency & $94 \%$ & $92 \%$ & $93 \%$ \\
\hline Extent protocol delivered as intended & $21 \%$ & $17 \%$ & $20 \%$ \\
\hline Measures of cost of implementation & $12 \%$ & $8 \%$ & $11 \%$ \\
\hline Average across Implementation components & $42 \%$ & $39 \%$ & $41 \%$ \\
\hline \multicolumn{4}{|l|}{ Maintenance } \\
\hline Assessed outcomes $>6$ months post intervention & $12 \%$ & $8 \%$ & $11 \%$ \\
\hline Indicators of program-level maintenance & $9 \%$ & $25 \%$ & $13 \%$ \\
\hline Measures of cost of maintenance & $6 \%$ & $8 \%$ & $7 \%$ \\
\hline Average across Maintenance components & $9 \%$ & $14 \%$ & $10 \%$ \\
\hline
\end{tabular}

reach indicators, while English articles were more likely to report on efficacy/effectiveness indicators. In general, the reviewed articles focused on reporting RE-AIM indicators that captured internal validity.

Consistent with findings from similar reviews $[20,21,23,24]$, the method to identify the target population and inclusion criteria were the most commonly reported indicators of reach, and exclusion criteria, participation rate and representativeness were the least reported. In contrast, Hoehner and colleagues found that the studies that they reviewed mainly reported on the characteristics of the target population, participation rate and recruitment strategies [15]. Our findings show that reports from physical activity interventions for Latin American populations are lacking information relevant to generalizability.

Similar to findings from previous reviews [20,21,24], we found that the efficacy/effectiveness dimension was the most reported across studies. The most reported indicators within this dimension were primary outcome results and percent of attrition, and the least reported indicators were the use of imputation procedures and the use of quality of life and/or potential negative outcomes measures. Similarly, Hoehner and colleagues reported that 
outcomes comparable to clinical guidelines were often reported while quality of life was seldom reported [15]. These and our findings indicate that physical activity interventions for Latin Americans may be overlooking quality of life as an important public health indicator of intervention impact.

For implementation, our findings were consistent with previous reports [22-24]. Intervention dose delivered was almost always reported. Delivery of intervention as intended was sometimes reported, and cost of intervention was seldom reported. Similarly, Hoehner and colleagues found that description of intervention components/frequency and description of the delivery agent were the most reported implementation indicators [15]. These findings show that information about the fidelity and costs of physical activity interventions for Latin Americans is insufficient. Finally, adoption and maintenance indicators were the least reported, which aligns with previous findings $[20,21,23,24]$. Within the adoption dimension, delivery agent expertise was the most reported indicator, followed by description of intervention location, which differs from a previous review [24]. Hoehner and colleagues report that the acknowledgement of intervention adoption in the setting was the most reported indicator in the articles reviewed [15]. The least reported adoption indicators were description of delivery agent, method to identify delivery agent and delivery agent/setting inclusion/exclusion criteria. Within the maintenance dimension, the most reported indicator was information on continued delivery, followed by outcomes assessed after six months, which differs from previous reviews $[20,21,23,24]$. Hoehner and colleagues found that the most reported maintenance indicator was acceptability of intervention followed by sustainability of intervention, and similar to our findings, that intervention institutionalization was seldom reported [15].

The difference between findings from the present and the Hoehner and colleagues review may be explained by the fact that we included different studies, employed a different data extraction tool and focused on different Latin American countries. For instance, only five of studies we included in this review were also included in the Hoehner and colleagues review, which exposes work that might not have been captured previously. Further, our extraction tool was focused capturing external validity items according to the RE-AIM framework, while the tool employed by Hoehner and colleagues focused did not employ the full RE-AIM model. Last, the majority of the studies included in the Hoehner and colleagues review were from Brazil, whereas in this review most of the studies came from the United States, followed by Chile, Mexico and Colombia. Nevertheless, our conclusions are similar in that more attention to, and reporting of, external validity factors is needed the literature reporting physical activity interventions for Latin Americans.

From this review, we have drawn the following recommendations that can help improve the reporting of intervention findings and ultimately their translation into public health practice in Latin America. For improving the generalizability of findings, the reporting of intervention findings should include information about the representativeness of the sample; that is, participation rate and the characteristics of participants and non-participants. A good example of such reporting is provided in Atehortúa et al., where authors reported how patients were identified and recruited, the inclusion/exclusion criteria, that $65 \%$ of the patients who were invited to participate entered the intervention and that these patients were similar to the population at the clinic [47]. Regarding effectiveness, physical activity interventions should include a quality of life measure, which is an important intervention outcome, especially from a public health perspective, since mental and physical wellbeing provide a critical check on the impact of a program [16]. Further, such interventions should report both positive and negative outcomes in order to ensure that program-related harms do not outweigh program benefits [16]. Except for the reporting of program negative outcomes, the paper by Atehortúa et al., is a good example where the authors reported having observed positive changes in the primary outcome (patients' cardiorespiratory fitness) and no changes in quality of life at program completion [47].

For implementation, the reporting of intervention fidelity and costs should be improved in order to promote the translation of physical activity interventions for Latin Americans across the continent. For example, Salinas et al., reported that 96 physical activity workshops were delivered over eight months (three 60-minute sessions per week), where $97 \%$ of the professors delivered the intervention as intended, and the cost per workshop was $\$ 1,200$ US dollars [72]. Information about the adoption and maintenance of physical activity interventions among Latin Americans is scarce, thereby limiting their transferability and potential for sustainability. The reporting of intervention adoption should include a description of intervention location, the method used to identify the staff who delivered the intervention and the rate of adoption at the staff and setting levels. For instance, Kain et al., reported that a school-based intervention to prevent obesity in children was delivered in a small municipality of Chile by dieticians and physical educators, where $100 \%$ of the schools selected actually participated in the intervention and $57 \%$ of teachers within the schools also adopted the intervention [61]. Finally, reports on the maintenance of intervention effects and implementation should improve; outcomes after six months, institutionalization of intervention and continuation of delivery should be reported. 
For instance, Ingram et al., reported physical activity outcomes two years after the program was complete and reported that internal financial resources to continue the program were obtained [60].

The implications of the present findings are threefold. First, our findings show that the reviewed literature focused on reporting internal validity factors and underscore the need to improve reporting on external validity factors associated with generalizability. These findings can inform the design, implementation and reporting of future physical activity interventions by outlining the external validity factors that are likely to promote their transferability across populations and settings. For instance, the Ciclovia program [8], in which automobile streets are closed for one day a week to promote active transportation, could be evaluated with special attention to the external validity factors highlighted in this review. Further, the Ciclovia program has been shown to be a cost-beneficial program [7] that could be adopted and promoted in other Latin American countries if information critical for generalizability were available. Second, our review showed a discrepancy in reporting proportions between English and Spanish studies, which suggests that a different priority may be given to internal and external validity factors between languages. This inconsistency could be addressed by using a validated framework, such as RE-AIM, and standardizing the reporting of physical activity interventions focusing on Latin Americans. Last, this review makes and important contribution to the existing research by exposing the research gap that exists between larger, more economically advanced countries and other Latin American countries. As shown in this and the Hoehner and colleagues review [15], large counties such as Brazil and United States have conducted many more studies than other, under-resourced Latin American countries.

\section{Limitations}

We only included experimental and quasi-experimental studies with pre and post assessments evaluating the efficacy/effectiveness of physical activity interventions targeting Latin Americans. This, unfortunately, excluded some studies of Ciclovia [7,8] and Agita [9], that are prominent physical activity promotion initiatives in Latin America. Second, we only focused on assessing the reporting across RE-AIM dimensions and did not report on the efficacy or effectiveness of the interventions as is typical in a systematic reviews. However, our review does document specific gaps in the reporting of key factors that have the potential to influence research to practice translation using a rigorous search strategy, well-defined inclusion and exclusion criteria, and validated data extraction tool.

\section{Conclusion}

This systematic review provides relevant information for the physical activity promotion field that can be used to ensure that interventions are representative of Latin Americans and intervention effects are consistent and replicable across settings. This review builds onto a body of knowledge that is still in its early stages and contributes to the development of the Latin American physical activity literature. Regardless of language of publication, physical activity intervention research for Latin Americans should increase the attention to, and measurement of, external validity and cost factors that are critical in the decision making process in practice settings and can increase the likelihood of translation into community or clinical practice.

\section{Additional files}

Additional file 1: Review Search Strings.

Additional file 2: Table of Studies Included.

\section{Competing interests}

The authors declare that they have no competing interests.

\section{Authors' contributions}

KG helped conceptualizing and designing of the review, acquired Spanish language articles data, conducted the analyses and interpretation of data, drafted the manuscript and has given final approval of the version to be published. PE conceptualized and designed the review, acquired English language articles data, helped conducting the analyses and interpretation of data, helped drafting the manuscript and has given final approval of the version to be published. SMH helped conceptualizing and designing the review, acquired English language articles data, helped conducting the analyses and interpretation of data, helped drafting the manuscript and has given final approval of the version to be published. SM helped

conceptualizing and designing the review, acquired English language articles data, helped conducting the analyses and interpretation of data, critically revised the manuscript and has given final approval of the version to be published. ES acquired Spanish language articles data, critically revised the manuscript and has given final approval of the version to be published. KCAB acquired English language articles data, critically revised the manuscript and has given final approval of the version to be published. LMB acquired English language articles data, critically revised the manuscript and has given final approval of the version to be published. FA acquired Spanish language articles, critically revised the manuscript and has given final approval of the version to be published. RL was the principal investigator on the grant funding that supported the review, helped with conceptualizing and designing the review, critically revised the manuscript and has given final approval of the version to be published.

\section{Acknowledgments}

This work was completed as part of a funded project called Multinational Collaboration to Increase Physical Activity in Hispanics (1R13CA162816) by the Applying Collaboration in Translational Investigation for Valuable Activity Recommendations (ACTIVAR) group. We thank Juan Lopez y Taylor, Edtna Jauregui, Charles Layne, Daniel O'Connor, Cynthia Castro, Lucie Levesque, Lorna McNeill and Teresia O'Connor who were involved in this Multinational Collaboration project and who provided support and feedback.

\section{Author details}

${ }^{1}$ School of Kinesiology and Health Studies, Queen's University, \#28 Division Street, Kingston, ONK7L 3N6, Canada. ${ }^{2}$ School of Kinesiology, University of British Columbia, 122-6081 University Blvd, Vancouver, BCV6K 1L7, Canada. ${ }^{3}$ Department of Human Nutrition, Post-Doctoral Research Fellow, Foods and 
Exercise, Fralin Translational Obesity Research Center, Virginia Tech, 1 Riverside Circle SW suite 104, Roanoke, VA 24016, USA. ${ }^{4}$ Virginia Tech, Human Nutrition, Foods and Exercise, 1981 Kraft Drive, Blacksburg, VA 24061, USA ${ }^{5}$ Virginia Tech, Human Nutrition, Foods and Exercise, Fralin Translational Obesity Research Center, 1981 Kraft Drive, Blacksburg, VA 24061, USA. ${ }^{6}$ Department of Health Disparities Research, The University of Texas M.D. Anderson Cancer Center, 1400 Pressler St., Unit 1440, Houston, TX 77030-3906, USA. ${ }^{7}$ Department of Human Nutrition, Foods and Exercise Fralin Translational Obesity Research Center, Virginia Tech, 1 Riverside Circle sw suite 104, Roanoke, VA 24016, USA. ${ }^{8}$ Professor, College of Nursing and Health Innovation, Arizona State University, 550 N. 3rd Street, Phoenix, AZ 85004, USA. ${ }^{9}$ Professor of Human Nutrition, Foods, \& Exercise, Virginia Tech, Co-Director of the Fralin Translational Obesity Research Center, Professor of Family Medicine, Virginia Tech Carilion School of Medicine, Senior Director of Research, Carilion Clinic, 1 Riverside Circle SW Suite \#104, Roanoke, VA 24016, USA.

Received: 13 September 2013 Accepted: 11 June 2014

Published: 17 June 2014

\section{References}

1. Bull FC, Armstrong TP, Dixon T, Ham S, Neiman A, Pratt M: Physical Inactivity. In Comparative quantification of health risks Global and regional burden of disease attributable to selected major risk factors. Edited by Ezzati M, Lopez AD, Rodgers A, Murray CJ. Geneva: World Health Organization; 2004:729-881

2. Booth FW, Laye MJ, Lees SJ, Rector RS, Thyfault JP: Reduced physical activity and risk of chronic disease: the biology behind the consequences. Eur J Appl Physiol 2008, 102:381-390.

3. Lee IM, Shiroma EJ, Lobelo F, Puska P, Blair SN, Katzmarzyk PT: Group ftLPASW: Effect of physical inactivity on major non-communicable diseases worldwide: an analysis of burden of disease and life expectancy. Lancet 2012, 280(9838):219-229.

4. WHO: Global health risks: mortality and burden of disease attributable to selected major risks. Geneva: World Health Organization; 2009.

5. Hallal PC, Andersen LB, Bull FC, Guthold R, Haskell W, Ekelund U: Global physical activity levels: surveillance progress, pitfalls, and prospects. Lancet 2012, 380(9838):247-257.

6. Hoehner CM, Soares J, Parra Perez D, Ribeiro IC, Joshu CE, Pratt M, Legetic BD, Malta DC, Matsudo VR, Ramos LR, Simões EJ, Brownson RC: Physical Activity Interventions in Latin America: A Systematic Review. Am J Prev Med 2008, 34(3):224-233. e224.

7. Montes F, Sarmiento OL, Zarama R, Pratt M, Wang G, Jacoby E, Schmid TL, Ramos M, Ruiz O, Vargas O, Michel G, Zieff SG, Valdivia JA, Cavill N, Kahlmeier S: Do health benefits outweigh the costs of mass recreational programs? An economic analysis of four Ciclovía programs. J Urban Health 2012, 89(1):153-170

8. Sarmiento O, Torres A, Jacoby E, Pratt M, Schmid TL, Stierling G: The Ciclovía-Recreativa: a mass-recreational program with public health potential. J Phys Act Health 2010, 2:S163-S180.

9. Matsudo SM, Matsudo VR, Araujo TL, Andrade DR, Andrade EL, de Oliveira LC, Braggion GF: The Agita São Paulo Program as a model for using physical activity to promote health. Pan Am J Public Health 2003 14(4):265-272

10. Pratt M, Brownson RC, Ramos LR, Malta DC, Hallal PC, Reis RS, Parra DC, Simoes EJ: Project GUIA: a model for understanding and promoting physical activity in Brazil and Latin America. J Phys Act Health 2010, 7(2):131-134.

11. Truman B, Smith-Akin CK, Hinman AR, Gebbie KM, Brownson R, Novick LF, Lawrence RS, Pappaioanou M, Fielding J, Evans CA, Guerra FA, Vogel-Taylor M, Mahan CS, Fullilove M, Zaza S: Developing the Guide to Community Preventive Services-overview and rationale. The Task Force on Community Preventive Services. Am J Prev Med 2000, 18(1):18-26.

12. Glasgow RE, Lichtenstein E, Marcus AC: Why Don't We See More Translation of Health Promotion Research to Practice? Rethinking the Efficacy-to-Effectiveness Transition. Am J Public Health 2003, 93(8):1261-1267.

13. Patrick K, Scutchfield FD, Woolf SH: External validity reporting in prevention research. Am J Prev Med 2008, 34:260-262.
14. Steckler A, McLeroy KR: The importance of external validity. Am J Public Health 2008, 98:9-10.

15. Hoehner CM, Ribeiro IC, Parra DC, Reis RS, Azevedo MR, Hino AA, Soares J, Hallal PC, Simões EJ, Brownson RC: Physical Activity Interventions in Latin America: Expanding and Classifying the Evidence. Am J Prev Med 2013, 44(3):e31-e40

16. Glasgow RE, Vogt TM, Boles SM: Evaluating the public health impact of health promotion interventions: the RE-AIM framework. Am J Public Health 1999, 89(9):1322-1327.

17. Estabrooks PA, Gyurcsik NC: Evaluating the impact of behavioral interventions that target physical activity: issues of generalizability and public health. Psychol Sport Exerc 2003, 4(1):41-55.

18. Antikainen I, Ellis R: A RE-AIM evaluation of theory-based physical activity interventions. J Sport Exercise Psy 2011, 33(2):198-214.

19. Glasgow RE, Vogt TM, Boles SM: Evaluating the public health impact of health promotion interventions: the RE-AIM framework. Am J Public Health 1999, 89(9):1322-1327.

20. Antikainen I, Ellis R: A RE-AIM Evaluation of Theory-Based Physical Activity Interventions. J Sport Exerc Psychol 2011, 33:198-214.

21. Estabrooks P, Dzewaltowski DA, Glasgow RE, Klesges LM: Reporting of Validity from School Health Promotion Studies Published in 12 Leading Journals, 1996-2000. J Sch Health 2003, 73(1):21-28.

22. Goode AD, Reeves MM, Eakin EG: Telephone-Delivered Interventions for Physical Activity and Dietary Behavior Change: An Updated Systematic Review. Am J Prev Med 2012, 42(1):81-88.

23. Vuillemin A, Rostami C, Maes L, Van Cauwenberghe E, Van Lenthe FJ, Brug J, De Bourdeaudhuij I, Oppert JM: Worksite physical activity interventions and obesity: a review of European studies (the HOPE project). Obes Facts 2011, 4(6):479-488.

24. White SM, McAuley E, Estabrooks PA, Courneya KS: Translating physical activity interventions for breast cancer survivors into practice: an evaluation of randomized controlled trials. Ann Behav Med 2009 37(1):10-19.

25. Akers J, Estabrooks PA, Davy BM: Translational research: Bridging the gap between long-term weight loss maintenance research and practice. J Am Diet Assoc 2010, 110(10):1511-1522.

26. Glasgow RE, Klesges LM, Dzewaltowski DA, Bull SS, Estabrooks P: The future of health behavior change research: what is needed to improve translation of research into health promotion practice? Ann Behav Med 2004, 27(1):3-12

27. Kessler RS, Purcell EP, Glasgow RE, Klesges LM, Benkeser RM, Peek CJ: What Does It Mean to Employ the RE-AIM Model? Eval Health Prof 2012, 36(1):44-66

28. Flay BR: Efficacy and effectiveness trials (and other phases of research) in the development of health promotion programs. Prev Med 1986, 15(5):451-474

29. Alhassan S, Sirard JR, Robinson TN: The effects of increasing outdoor play time on physical activity in Latino preschool children. Int J Pediatr Obes 2007, 2(3):153-158

30. Coleman KJ, Farrell MA, Rocha DA, Hayashi T, Hernandez M, Wolf J, Lindsay S: Readiness to be physically active and self-reported physical activity in low income Latinas, California WISEWOMAN, 2006-2007. Prev Chronic Dis 2012, 9:1-8

31. Colín-Ramírez E, Castillo-Martínez L, Orea-Tejeda A, Vergara-Castañeda A, Keirns-Davis C, Villa-Romero A: Outcomes of a school-based intervention (RESCATE) to improve physical activity patterns in Mexican children aged 8-10 years. Health Educ Res 2010, 25(6):1042-1049.

32. Crews DJ, Lochbaum MR, Landers DM: Aerobic physical activity effects on psychological well being in low-income Hispanic children. Percept Mot Skills 2004, 98(1):319-324

33. Eakin EG, Bull S, Riley SK, Reeves MM, Gutierrez S, McLaughlin P: Recruitment and retention of Latinos in a primary care-based physical activity and diet trial: the Resources for Health study. Health Educ Res 2007, 22(3):361-371.

34. Kain BJ, Uauy DR, Leyton DB, Cerda RR, Olivares CS, Vio DF: Efectividad de una intervención en educación alimentaria y actividad física para prevenir obesidad en escolares de la ciudad de Casablanca, Chile (2003-2004). Rev Med Chil 2008, 136:22-30.

35. Keller CS, Cantue A: Camina por Salud: Walking in Mexican-American women. Appl Nurs Res 2008, 21(2):110-113. 
36. King DK, Estabrooks PA, Strycker LA, Toobert DJ, Bull SS, Glasgow RE: Outcomes of a multifaceted physical activity regimen as part of a diabetes self-management intervention. Ann Behav Med 2006, 31(2):128-137.

37. Molina SE, González JJA, León PJA: Efectos de dos programas de entrenamiento sobre la aptitud física metabólica en adultos mayores. Hacia la Promocion de la Salud 2010, 15(5):45-63.

38. Muñoz CKA, Salazar GBC: Ejercicio de resistencia muscular en adultos con diabetes mellitus tipo 2. Rev Lat Am Enfermagem 2005, 13:21-26.

39. O'Connor TM, Hilmers A, Watson K, Baranowski T, Giardino AP: Feasibility of an obesity intervention for paediatric primary care targeting parenting and children: Helping HAND. Child Care Health Dev 2011, 39(1):141-149.

40. Olvera N, Bush JA, Sharma SV, Knox BB, Scherer RL, Butte NF: BOUNCE: a community-based mother-daughter healthy lifestyle intervention for low-income Latino families. Obesity 2010 18(1):S102-S104

41. Ramírez-Vélez R, de Plata AC A, Mosquera-Escudero M, Ortega JG, Salazar B, Echeverri I, Saldarriaga-Gil W: Efecto del ejercicio físico aeróbico sobre el consumo de oxígeno de mujeres primigestantes saludables. Estudio clínico aleatorizado. Rev Colomb Obstet Ginecol 2011, 62:15-23.

42. Romero Z, Villas $P$, Semper $T$, Jorgensen $L$ : Use of pedometers to promote physical activity in older Mexican American females. Revista Salud Publica y Nutricion 2008, 9(3)

43. Spruijt-Metz D, Belcher B, Anderson D, Lane CJ, Chou CP, Salter-Venzon D, Davis JN, Hsu YW, Neuhouser ML, Richey JM, McKenzie TL, McClain A, Goran Ml, Weigensberg MJ: A high-sugar/low-fiber meal compared with a low-sugar/high-fiber meal leads to higher leptin and physical activity levels in overweight Latina females. J Am Diet Assoc 2009, 109(6):1058-1063.

44. Spruijt-Metz D, Nguyen-Michel S, Goan M, Chou C-P, Huang T: Reducing Sedentary Behavior in Minority Girls via a Theory-based, Tailored Classroom Media Intervention. Int J Pediatr Obes 2008, 3(3):240-248

45. Treviño RP, Yin Z, Hernandez A, Hale DE, Garcia OA, Mobley C: Impact of the Bienestar school-based diabetes mellitus prevention program on fasting capillary glucose levels: a randomized controlled trial. Arch ediatrics Adolesc Med 2004, 158(9):911-917.

46. Wing RR, Hamman RF, Bray GA, Delahanty L, Edelstein SL, Hill JO, Horton ES, Hoskin MA, Kriska A, Lachin J, Mayer-Davis EJ, Pi-Sunyer X, Regensteiner JG, Venditti B, Wylie-Rosett J, Diabetes Prevention Program Research Group: Achieving weight and activity goals among diabetes prevention program lifestyle participants. Obes Res 2004, 12(9):1426-1434

47. Atehortúa DS, Gallo JA, Rico M, Durango L: Efecto de un programa de rehabilitación cardiaca basado en ejercicio sobre la capacidad física, la función cardiaca y la calidad de vida, en pacientes con falla cardiaca. Revista Colomb de Cardiología 2011, 18(1):25-36.

48. Ayala GX: Effects of a promotor-based intervention to promote physical activity: Familias Sanas y Activas. Am J Public Health 2011, 101(12):2261-2268.

49. Bacardí-Gascón M, Rosales-Garay P, Jiménez-Cruz A: A diabetes intervention program of physical activity carried out at primary care settings in Mexico. Diabetes Res Clin Pract 2005, 68(2):135-140.

50. Balcázar H, Alvarado M, Hollen ML, Gonzalez-Cruz Y, Pedregón V: Evaluation of Salud Para Su Corazón (Health for your Heart) - National Council of La Raza Promotora Outreach Program. Prev Chronic Dis 2005, 2(3):A09.

51. Barroso CS, Kelder $S H$, Springer $A E$, Smith $C L$, Ranjit $N$, Ledingham $C$, Hoelscher DM: Senate Bill 42: Implementation and Impact on Physical Activity in Middle Schools. J Adolesc Health 2009, 45(3):S82-590.

52. Bonhauser M, Fernandez G, Püschel K, Yañez F, Montero J, Thompson B, Coronado G: Improving physical fitness and emotional well-being in adolescents of low socioeconomic status in Chile: results of a school-based controlled trial. Health Promot Int 2005, 20(2):113-122.
53. Carreño J, Vyhmeister G, Grau L, Ivanovic D: A health promotion programme in Adventist and non-Adventist women based on Pender's model: a pilot study. Public Health 2006, 120(4):346-355.

54. Coleman KJ, Ocana LL, Walker C, Araujo RA, Gutierrez V, Shordon M, Oratowski-Coleman J, Philis-Tsimikas A: Outcomes From a Culturally Tailored Diabetes Prevention Program in Hispanic Families From a Low-Income School: Horton Hawks Stay Healthy (HHSH). Diabetes EduC 2010, 36(5):784-792.

55. Coleman KJ, Tiller CL, Sanchez J, Heath EM, Sy O, Milliken G, Dzewaltowski DA: Prevention of the epidemic increase in child risk of overweight in low-income schools: The el paso coordinated approach to child health. Arch Pediatr Adolesc Med 2005, 159(3):217-224

56. Dauenhauer BD, Keating XD: The Influence of Physical Education on Physical Activity Levels of Urban Elementary Students. Res Q Exerc Sport 2011, 82(3):512-520.

57. Díaz MX, Mardones HMA, Bastias CM, Carreño AR, Retama MC: Pausa activa como factor de cambio en actividad física en funcionarios públicos. Revista Cubana de Salud Publica 2011, 37(3):306-313.

58. Dornelas E, Stepnowski R, Fischer E, Thompson P: Urban Ethnic Minority Womens Attendance at Health Clinic vs Church Based Exercise Programs. J Cross Cult Gerontol 2007, 22(1):129-136.

59. Hawthorne A, Shaibi G, Gance-Cleveland B, McFall S: Grand Canyon Trekkers: School-Based Lunchtime Walking Program. J Sch Nurs 2011, 27(1):43-50.

60. Ingram M, Piper R, Kunz S, Navarro C, Sander A, Gastelum S: Salud Si: A Case Study for the Use of Participatory Evaluation in Creating Effective and Sustainable Community-Based Health Promotion. Fam Community Health 2012, 35(2):130-138

61. Kain J, Concha F, Salazar G, Leyton B, Rodríguez MP, Ceballos X, Vio F: Prevención de obesidad en preescolares y escolares de escuelas Municipales de una Comuna de Santiago de Chile: proyecto piloto 2006. Arch Latinoam Nutr 2009, 59:139-146.

62. Keller C, Treviño RP: Effects of two frequencies of walking on cardiovascular risk factor reduction in Mexican American women. Res Nurs Health 2001, 24(5):390-401.

63. Kong AS, Burks N, Conklin C, Roldan C, Skipper B, Scott S, Sussman AL, Leggott J: A Pilot Walking School Bus Program to Prevent Obesity in Hispanic Elementary School Children: Role of Physician Involvement With the School Community. Clin Pediatr 2010, 49(10):989-991.

64. Lucumí DI, Sarmiento OL, Forero R, Gomez LF, Espinosa G: Community Intervention to Promote Consumption of Fruits and Vegetables, Smoke-free Homes, and Physical Activity Among Home Caregivers in Bogotá. Colomb Prev Chronic Dis 2006, 3(4):A120

65. Martyn-Nemeth PA, Vitale GA, Cowger DR: A Culturally Focused Exercise Program in Hispanic Adults With Type 2 Diabetes: A Pilot Study. Diabetes Educ 2010, 36(2):258-267

66. Mier N, Tanguma J, Millard AV, Villarreal EK, Alen M, Ory MG: A Pilot Walking Program for Mexican-American Women Living in Colonias at the Border. Am J Health Promot 2011, 25(3):172-175.

67. Millard AV, Graham MA, Wang X, Mier N, Sanchez ER, Flores I, Elizondo-fournier M: Pilot of a Diabetes Primary Prevention Program in a Hard-to-Reach, Low-Income, Immigrant Hispanic Population. J Immigr Minor Health 2011, 13(5):906-913.

68. Mosso CC, Santander VP, Pettinelli RP, Valdés GM, Celis BM, Espejo SF, Navarro ML, Sepúlveda VF: Evaluación de una intervención en actividad física en niños con síndrome de Down. Rev Chil Pediatr 2011, 82:311-318

69. Romero AJ: A pilot test of the Latin active hip hop intervention to increase physical activity among low-income Mexican-American adolescents. Am J Health Promot 2012, 26(4):208-211.

70. Roselló AM, Guzmán PS, Bolaños AM: Efecto de un programa de rehabilitación cardíaca en la alimentación, peso corporal, perfil lipídico y ejercicio físico de pacientes con enfermedad coronaria. Rev Costarric Cardiol 2001, 3:15-20.

71. Sáenz-Soto NE, Gallego EC: Efecto de intervención física sobre alimentación y actividad física en adolescentes mexicanos con obesidad. Texto \& Contexto Enfermagem 2004, 13(1):17-25. 
72. Salinas CJ, Bello SM, Flores CA, Carbullanca LL, Torres GM: Actividad física integral con adultos y adultos mayores en chile: resultados de un programa piloto. Rev Chil Nutr 2005, 32(3):215-224

73. Sandoval CC, Camargo ML, González ODM, Vélez RYP: Programa de ejercicio físico para los adultos mayores del Club Nueva Vida de la Ciudad de Tunja. Revista de Ciencias de la Salud 2007, 5(2):60-71.

74. Staten LK, Scheu LL, Bronson D, Peña V, Elenes J: Pasos Adelante: the effectiveness of a community-based chronic disease prevention program. Prev Chronic Dis 2005, 2(1):1-11.

doi:10.1186/1479-5868-11-77

Cite this article as: Galaviz et al:: Physical activity promotion in Latin American populations: a systematic review on issues of internal and external validity. International Journal of Behavioral Nutrition and Physical Activity 2014 11:77.

\section{Submit your next manuscript to BioMed Central and take full advantage of:}

- Convenient online submission

- Thorough peer review

- No space constraints or color figure charges

- Immediate publication on acceptance

- Inclusion in PubMed, CAS, Scopus and Google Scholar

- Research which is freely available for redistribution 